\title{
LET'S POSITIVIZE OUR NEGATIVE EUGENICS
}

\author{
A. E. Hamilton, New York, N. Y.
}

$\mathrm{I}^{\mathrm{p}}$ F WE are going to get the moral support of the people for programs of segregating and colonizing our hereditary defectives in a really large way, we will have to present a program that is alive with the spirit of "something to do." Merely caging people who are a nuisance doesn't arouse much genuine human interest, or at best this interest is academic. But tell a man that you can take a lot of human damaged goods and make it into a useful constructive factor in our national life, and he will sit up and listen.

Charles Bernstein, Superintendent of the Rome State Custodial Asylum, at Rome, New York, has given negative eugenics a golden text that shines.

He turned twenty-five of his higher grade inmate boys into Boy Scouts (all of them passed the tenderfoot requirements), uniformed them and sent them up into the Adirondacks for a month of summer camping last October. He asked Governor Whitman if these boys couldn't be used in reforesting work. They had plenty of time, they loved to work out-of-doors, they were well superintended by George Kuehn, a natureloving Scout Master who could get that gang of state wards to do anything within reach of their possibilities, and do it happily and well. Governor Whitman was willing, but some small-minded political parasites found a technical objection to State employment of such labor and threw sand in the bearings of the enterprise. But Bernstein persisted.

The boys were sent up to camp, and incidentally a carload of seedling spruce

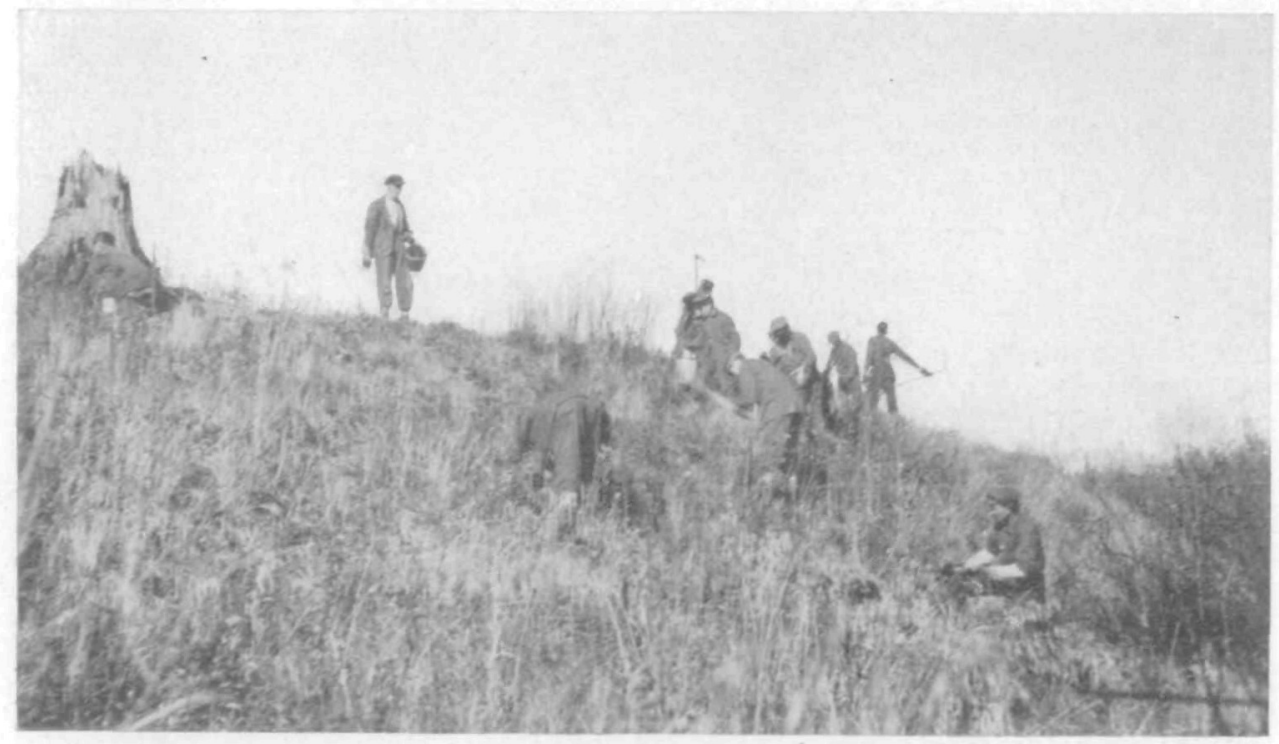

THIS BARE HILL WILL BECOME A FOREST

And the change will be due to a bunch of boys who now represent only waste human material, in most places. The feebleminded are not able to compete on equal terms with the normal, in the struggle of the world's work, but they are abundantly able to do many kinds of work, and do it well, if they have proper direction. They might be made an asset of the State, instead of the liability they are at present, if more people had a sympathetic understanding of their possibilities. (Fig. 10.) 


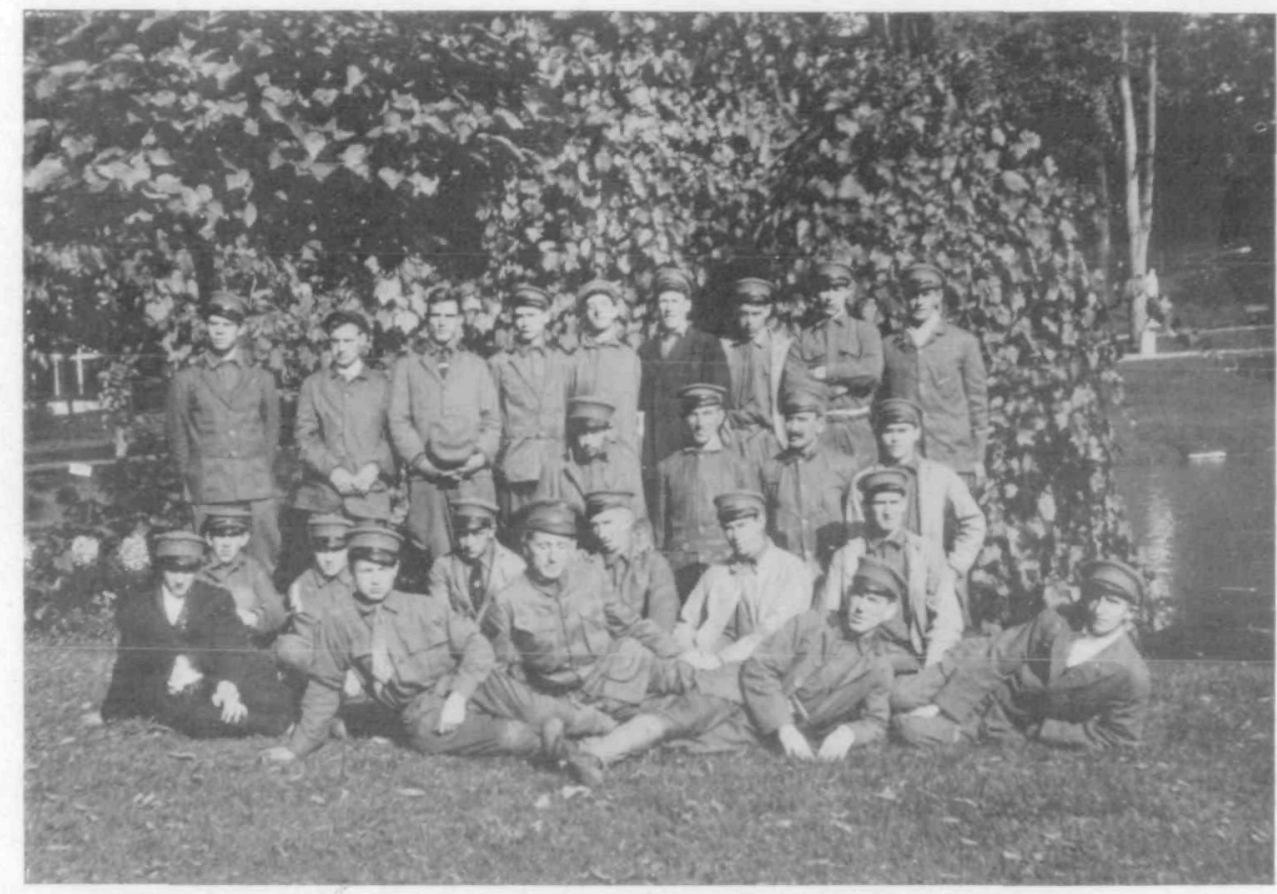

DO THESE BOYS LOOK DANGEROUS?

Popular ignorance tends, to confuse the feebleminded with the insane and imagine that they should'be caged in the interests of public safety. As a fact, most of them are strong, healthy individuals who are, mentally, merely good-natured, irresponsible children. They require careful supervision, but given that they may live not only happy but productive lives. The campaign for "negative eugenics" should be devoted to putting the defectives not only where they can do no harm but even more to putting them where they can do good. The conservation team here shown is made up from boys at the Rome State Custodial Asylum, N.Y. (Fig. 11.)

was left on a siding of the railroad nearby. The door of this car was open, and boys will be boys. Two by two they carried off the young trees, and planted them over a space of some one hundred and fifty acres. They did the work admirably, so well indeed that the State Commissioner of Conservation commended it warmly, and said it rąnked as high as any work done by regular paid labor. Just one hundred and fifty thousand trees were set out, all in a spirit of fun and play. The keep of these boys as state wards, plus the cost of transportation, amounted to $\$ 400$. The net value to the State of the work they did was $\$ 1,000$ and in twenty years time there will be a broad green monument to the boys' memory.

There are hundreds of thousands of acres of national land that need re- foresting and conservation work. There are several hundred thousand unfortunate young men and boys who cannot compete favorably with their fellows in the world who could do this work if they were rightly directed. Camp colonies in summer, transportation southward in cold weather for work down there, institutional housing in winter where necessary-all these things are coming, and they will come all the more quickly as people are told such stories as this, and stories such as Alexander Johnson, of Vineland, can tell by the ream of the possibilities that lie in subnormal nervous systems.

Eugenics will make progress just about in proportion as it eliminates its emphasis on pathology and concentrates on the positive aspects of human possibility. 